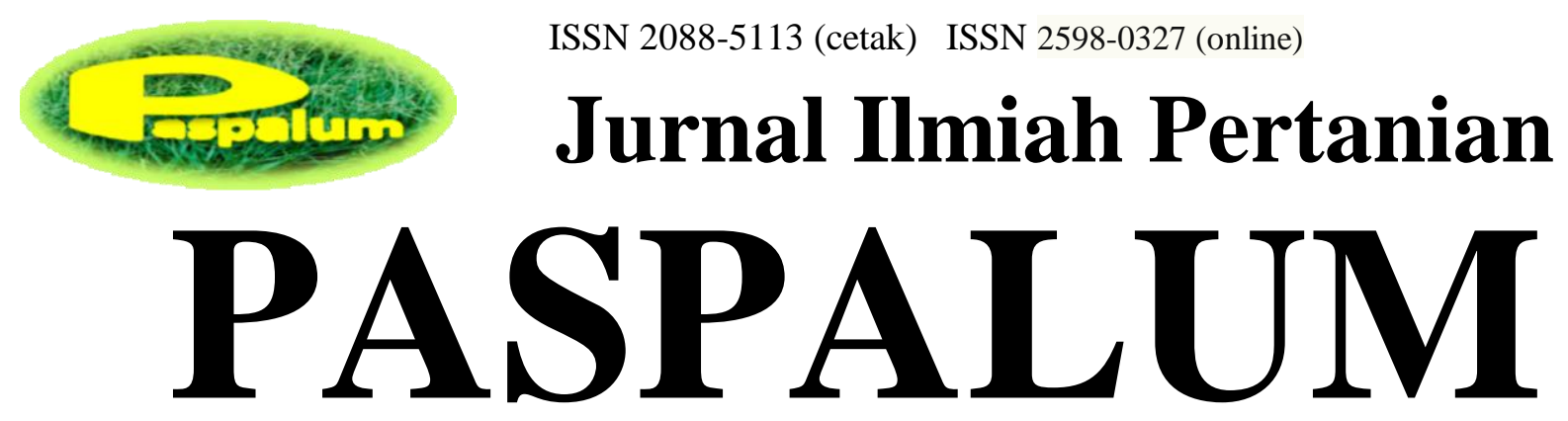

\author{
Vol. 7 No. 1 Bulan Maret Tahun 2019 \\ http://journal.unwim.ac.id/index.php/paspalum
}

\title{
Kemampuan Agroforestri Berbasis Kopi (Coffea arabica) dalam Menyimpan Cadangan Karbon
}

\author{
Fahriza Luth, Hadi Setiyono \\ Fakultas Kehutanan Universitas Winaya Mukti Bandung Jawa Barat. \\ rhiezatech75@gmail.com
}

Diterima tgl 3 Januari 2019 dan disetujui untuk diterbitkan tgl 15 Maret 2019

\begin{abstract}
Each type of forest ecosystem and the species in it have different abilities to absorb $\mathrm{CO}_{2}$ and produce biomass. Coffee-based agroforestry is thought to be able to increase the ability of forests to store carbon as a result of increasing species composition and density of plants in these forest areas. This study aims to determine the composition of plants and carbon stocks stored in coffee-based agroforestry forests in LMDH Paniis RPH Rancakalong BKPH East Manglayang KPH Sumedang Perum Perhutani Regional Division West Java and Banten. This study uses survey and laboratory methods. Data collection is done by collecting data directly at the research location, which is in the agroforestry forest area and natural forest area (as a comparison). Data obtained through observations in the field and laboratory are in the form of tree names, wood density, tree biomass and carbon stocks from biomass. The result shows that the agroforestry forest composition at LMDH Paniis RPH Rancakalong BKPH East Manglayang KPH Sumedang within 17,14 ha consists of Pine (Pinus mercusii), Big-leaf Mahogany (Swietenia macrophylla), Clove (Syzygium aromaticum) dan Coffee (Coffea arabica). The carbon stock is $1.869,73 \mathrm{~kg} / \mathrm{ha}$ in agroforestry forest, $2.618,32 \mathrm{~kg} / \mathrm{ha}$ in primary natural forest, and 1.460,91 kg/ha in secondary natural forest. Agroforestry forest has more carbon stock than the secondary natural forest, but agroforestry forest has less carbon stock than primary natural forest.
\end{abstract}

Keywords : Agroforestry, Coffee, Carbon Stock.

\begin{abstract}
Abstrak
Setiap tipe ekosistem hutan dan jenis yang ada di dalamnya mempunyai kemampuan yang berbeda-beda dalam menyerap $\mathrm{CO}_{2}$ dan menghasilkan biomassa. Agroforestri berbasis kopi diduga dapat meningkatan kemampuan hutan dalam menyimpan karbon sebagai akibat dari bertambahnya komposisi jenis dan kerapatan tanaman di kawasan hutan tersebut. Penelitian ini bertujuan untuk mengetahui komposisi tanaman dan cadangan karbon yang tersimpan pada hutan agroforestri berbasis kopi di LMDH Paniis RPH Rancakalong BKPH Manglayang Timur KPH Sumedang Perum Perhutani Divisi Regional Jawa Barat dan Banten. Kajian ini menggunakan metode survey dan laboratorium. Pengumpulan data dilakukan dengan pengambilan data langsung di lokasi penelitian, yaitu pada kawasan hutan agroforestri dan kawasan hutan alam (sebagai pembanding). Data yang diperoleh melalui pengamatan di lapangan dan di laboratorium yaitu berupa nama pohon, berat jenis kayu,
\end{abstract}


biomassa pohon dan cadangan karbon dari biomassa. Hasil kajian ini menunjukkan bahwa komposisi hutan agroferestri di LMDH Paniis RPH Rancakalong BKPH Manglayang Timur KPH Sumedang dengan luasan 17,14 ha terdiri dari pohon Pinus (Pinus mercusii), Mahoni daun lebar (Swietenia macrophylla), Cengkeh (Syzygium aromaticum) dan Kopi (Coffea arabica). Adapun cadangan karbon tersimpan yaitu sebesar $1.869,73 \mathrm{~kg} / \mathrm{ha}$ pada hutan agroferestri, $2.618,32 \mathrm{~kg} / \mathrm{ha}$ pada hutan alam primer dan 1.460,91 kg/ha pada hutan alam sekunder. Hutan agroforestri memiliki cadangan karbon lebih tinggi dibandingkan hutan alam sekunder namun lebih rendah dibandingkan hutan alam primer.

Kata kunci : Agroforestri, Kopi, Cadangan karbon.

\section{PENDAHULUAN}

Karbon di permukaan bumi tersimpan dalam empat reservoir, yakni fosil dan formasi batuan, atmosfer, samudra dan ekosistem daratan termasuk hutan (Kauppi, 2003). Hutan mengabsorpsi $\mathrm{CO}_{2}$ selama proses fotosintesis dan menyimpannya sebagai materi organik dalam biomassa tanaman. Proses penimbunan $\mathrm{C}$ dalam tubuh tanaman hidup dinamakan proses sekuestrasi (Csequestration). Dengan demikian mengukur jumlah $\mathrm{C}$ yang disimpan dalam tubuh tanaman hidup (biomassa) pada suatu lahan dapat menggambarkan banyaknya $\mathrm{CO}_{2}$ di atmosfer yang diserap oleh tanaman. Sedangkan pengukuran $\mathrm{C}$ yang masih tersimpan dalam bagian tumbuhan yang telah mati (nekromasa) secara tidak langsung menggambarkan $\mathrm{CO}_{2}$ yang tidak dilepaskan ke udara lewat pembakaran (Hairiah and Subekti, 2007).

Setiap tipe ekosistem hutan dan jenis yang ada di dalamnya mempunyai kemampuan yang berbeda-beda dalam menyerap $\mathrm{CO}_{2}$ dan menghasilkan biomassa. Sistem agroforestri diperkirakan memiliki potensi yang tinggi dalam penyerapan karbon di atmosfer. Menurut Utami et. al. (2003) agroforestri adalah salah satu sistem pengelolaan lahan yang berfungsi produktif dan protektif. Sistem agroforestri berkontribusi mengurangi peningkatan $\mathrm{CO}_{2}$ atmosfer dan gas rumah kaca lainnya dengan cara meningkatkan karbon dalam tanah dan mengurangi tekanan terhadap hutan akibat deforestasi, dimana karbon yang berasal dari $\mathrm{CO}_{2}$ tersebut diambil oleh tanaman dan disimpan dalam bentuk biomassa. Walaupun peran agroforestri dalam mempertahankan cadangan karbon di daratan masih lebih rendah dibandingkan dengan hutan alam, tetapi sistem ini dapat dijadikan suatu tawaran yang mampu memberikan harapan besar dalam meningkatkan cadangan karbon pada lahan-lahan terdegradasi (Widianto et al., 2003).

Di KPH Sumedang Perum Perhutani Divisi Regional Jawa Barat dan Banten telah dilaksanakan kegiatan agroforestri dengan mengkombinasikan tanaman kopi di bawah tegakan pinus sebagai tanaman pokok dalam produksi Perhutani, tepatnya di LMDH Paniis RPH Rancakalong BKPH Manglayang Timur. Agroforestri berbasis kopi diduga mampu meningkatan kemampuan hutan dalam menyimpan karbon sebagai akibat dari bertambahnya komposisi jenis dan kerapatan tanaman di kawasan hutan tersebut. Untuk mengetahui berapa besar kemampuan agroforestri berbasis kopi di kawasan hutan lindung jenis pinus (Pinus mercusii), maka perlu dilakukan penelitian berjudul "Kemampuan Agroforestri Berbasis Kopi (Coffea arabica) dalam Menyimpan Cadangan Karbon".

Penelitian ini bertujuan untuk mengetahui komposisi tanaman dan cadangan karbon yang tersimpan pada hutan agroforestri berbasis kopi di LMDH Paniis RPH Rancakalong BKPH Manglayang Timur KPH Sumedang.

\section{METODE}

Kajian ini dilaksanakan di kawasan hutan lindung RPH Rancakalong petak 4G BKPH Manglayang Timur KPH Sumedang Perum Perhutani Divisi Regional Jawa Barat dan Banten dengan luas 17,14 hektar. Secara topografis lokasi ini bergelombang dan berbukit dengan ketinggian $700-1.700$ meter di atas permukaan laut dan curah hujan ratarata $1.251 \mathrm{~mm}$ per tahun. Dasar pemilihan LMDH Paniis sebagai lokasi penelitian dilakukan secara sengaja dengan pertimbangan bahwa sistem agroforestri telah berjalan di 
LMDH Paniis melalui program PHBM dan LMDH Paniis merupakan LMDH terbaik dan percontohan di KPH Sumedang Perum Perhutani Divisi Regional Jawa Barat dan Banten. Selain itu pengujian dilakukan di Laboratorium Teknologi Hasil Hutan Fakultas Kehutanan Universitas Winaya Mukti.

Bahan yang digunakan dalam penelitian ini adalah kawasan hutan alam dan hutan lindung yang berisi tegakan Pinus berumur 25 tahun dengan jarak tanam $5 \mathrm{~m} \times 5 \mathrm{~m}$ yang yang dikombinasikan dengan tanaman Kopi berumur 3 tahun dengan jarak tanam 2,5 $\mathrm{m} \mathrm{x}$ 2,5 m. Selain itu terdapat juga pohon Mahoni berumur 5 tahun dan Cengkeh berumur 3 tahun. Sedangkan alat yang digunakan adalah phi band, gunting stek, timbangan analitik, hagameter, talleysheet, kamera, peralatan herbarium, oven, kalkulator dan alat tulis.

Metode yang digunakan dalam penelitian ini adalah metode survey dan laboratorium. Pengumpulan data dilakukan dengan pengambilan data langsung di lokasi penelitian, yaitu pada kawasan hutan agroforestri dengan luas 17,14 hektar dan kawasan hutan alam dengan luas 150 hektar (sebagai pembanding). Hutan agroforestri yang berada dikawasan LMDH Paniis adalah hutan pinus dengan kelas umur yang sama dan jarak tanam yang seragam serta tanaman kopi yang memiliki umur dan jarak tanam seragam pula, sehingga dapat dimasukkan dalam satu klaster. Hutan alam di desa Pangadegan dengan luas 150 ha dibagi menjadi dua LMU (Land Mapping Unit) berdasarkan jenis tanah, curah hujan dan ketinggian. LMU 1 yaitu hutan alam primer sedangkan LMU 2 hutan alam sekunder.

Data dalam penelitian ini terdiri dari data primer dan data sekunder. Data primer merupakan data yang diperoleh melalui pengamatan di lapangan dan di laboratorium yaitu berupa nama pohon, berat jenis kayu, biomassa pohon dan cadangan karbon dari biomassa. Data sekunder adalah data yang diperoleh dari sumber kepustakaan yang menunjang dalam penelitian.

Metode pengambilan data dilakukan menggunakan desain plot sampling dengan intensitas sampling sebesar 2,5\% (Permenhut nomor P.67/Menhut-II/2006). Plot sampling berbentuk persegi empat berukuran $40 \mathrm{~m}$ x 5 $m$ untuk pengukuran cadangan karbon dengan DBH (Diameter Breast Height) $5 \mathrm{~cm}$ hingga $30 \mathrm{~cm}$ (lingkar/lilit pohon $15 \mathrm{~cm}-95 \mathrm{~cm}$ ) dan plot ukuran $100 \mathrm{~m}$ x $20 \mathrm{~m}$ untuk pohon yang besar (DBH > $30 \mathrm{~cm}$ ) (Hairiah et al., 2011). Peletakkan plot sampel dilakukan secara sistematik menggunakan garis transek. Jumlah plot sampel pada tiap kawasan dapat dilihat pada Tabel 1.

Tabel 1. Jumlah Plot Sampel pada Tiap Kawasan.

\begin{tabular}{|c|c|c|c|c|}
\hline$\overline{\text { No }}$ & Kawasan & $\begin{array}{l}\text { Luas } \\
\text { (ha) }\end{array}$ & $\begin{array}{l}\text { Ukuran Plot } \\
\text { Sampel }\end{array}$ & $\begin{array}{l}\sum \text { Plot } \\
\text { Sampel }\end{array}$ \\
\hline 1. & Agroforestri & 17,14 & $\begin{array}{c}100 \mathrm{~m} \times 20 \mathrm{~m} \\
40 \mathrm{~m} \times 5 \mathrm{~m}\end{array}$ & $\begin{array}{c}3 \\
22\end{array}$ \\
\hline \multirow[t]{2}{*}{2.} & $\begin{array}{l}\text { Hutan alam } \\
\text { primer }\end{array}$ & 17,12 & $100 \mathrm{~m} \times 20 \mathrm{~m}$ & 3 \\
\hline & & & $40 \mathrm{~m} \times 5 \mathrm{~m}$ & 22 \\
\hline \multirow[t]{2}{*}{3.} & $\begin{array}{l}\text { Hutan alam } \\
\text { sekunder }\end{array}$ & 132,85 & $100 \mathrm{~m} \times 20 \mathrm{~m}$ & 17 \\
\hline & & & $40 \mathrm{~m} \times 5 \mathrm{~m}$ & 166 \\
\hline
\end{tabular}

Pengukuran cadangan karbon dilakukan hanya pada bagian tanaman hidup di atas permukaan tanah melalui beberapa prosedur yaitu : (1) penentuan nama pohon dan kerapatan jenis pohon; (2) penentuan biomassa pohon; dan (3) penentuan cadangan karbon.

Nama jenis pohon diperoleh dari temuan langsung di lapangan yang kemudian dimasukan kedalam tallysheet. Pengenalan nama jenis pohon tersebut bertujuan untuk mencari nilai kerapatan jenis $(\mathrm{KJ})$ pohon pada daftar KJ kayu pohon yang ada. Kerapatan jenis kayu, diperoleh dari db.worldagroforestry.org (Tree Funcional Attributes and Ecological. Database Wood Dencity). Bila pohon yang diukur belum terdaftar, maka untuk memperoleh kerapatan jenis kayu tersebut dilakukan pengukuran menggunakan metode pengovenan pada suhu $100^{\circ} \mathrm{C}$ selama 48 jam untuk mengetahui berat kering kayu tersebut. Selanjutnya untuk mengetahui kerapatan jenis dihitung dengan menggunakan rumus yang dikutip dari Hairiah and Subekti (2007) : 


$$
\begin{aligned}
\mathrm{KJ}\left(\mathrm{g} / \mathrm{cm}^{3}\right) & \left.=\frac{\mathrm{BK}(\mathrm{g})}{V\left(\mathrm{~cm}^{3}\right)} \quad \ldots \ldots \ldots \ldots \ldots \ldots \ldots\right) \\
\text { Dimana }: \mathrm{KJ} & =\text { Kerapatan jenis }\left(\mathrm{g} / \mathrm{cm}^{3}\right) \\
\mathrm{BK} & =\text { Berat kering }(\mathrm{g}) \\
\mathrm{V} & =\text { Volume }\left(\mathrm{cm}^{3}\right)
\end{aligned}
$$

Sedangkan untuk mengetahui volume dihitung dengan menggunakan rumus :

Volume $\left(\mathrm{cm}^{3}\right)=\pi \mathrm{R}^{2} \mathrm{~T}$

Dimana: $\pi=3,14$

$\mathrm{R}=$ Jari-jari potongan kayu $=1 / 2 \mathrm{x}$ Diameter $(\mathrm{cm})$

$\mathrm{T}=$ Panjang kayu $(\mathrm{cm})$

Pengukuran biomassa pohon dilakukan dengan menaksir volume pohon (tanpa melakukan perusakan atau non destructive). Volume pohon ditaksir dari ukuran diameter batangnya, yang diukur setinggi dada (DBH) atau 1,3 m dari permukaan tanah). Tinggi pohon diukur untuk mempertinggi akurasi estimasi volume pohon.

Dalam pengukuran diameter pohon tidak semua posisi pohon berada pada kondisi tegak sempurna, maka dari itu cara penentuan titik pengukuran DBH batang pohon berbanir, bergelombang, bercabang rendah atau pada lahan berlereng dilakukan dengan memperhatikan kondisi tegak pohon di lapangan.

Penghitungan biomassa pohon dihitung dengan menggunakan rumus yang dikutip dari Hairiah and Subekti (2007) :

$$
\mathrm{B}_{\mathrm{p}}=\mathrm{V}_{\mathrm{p}} \times \mathrm{Kj}_{\mathrm{p}=\ldots \mathrm{gr}}
$$

Dimana :

$\mathrm{B}_{\mathrm{p}}=$ Biomassa pohon.

$\mathrm{V}_{\mathrm{p}}=$ Volume pohon

$\mathrm{KJ}_{\mathrm{p}}=$ Kerapatan jenis pohon

Setelah jumlah biomassa pohon diketahui selanjutnya dapat dihitung cadangan karbon dari biomassa. Penghitungan cadangan karbon dari biomassa dilakukan menggunakan rumus sebagai berikut :

$$
\mathrm{C}_{\mathrm{b}}=\mathrm{B} \times \% \mathrm{C}_{\text {Organik }}
$$

Dimana:

$$
\begin{array}{ll}
\mathrm{C}_{\mathrm{b}} & =\text { Cadangan karbon dari biomassa }(\mathrm{kg}) . \\
\mathrm{B} & =\text { Total biomassa }(\mathrm{kg}) \\
\% \mathrm{C}_{\text {Organik }}= & \text { Nilai persentase cadangan karbon } \\
& 47 \% .
\end{array}
$$

\section{HASIL DAN PEMBAHASAN}

\section{Komposisi Tanaman}

\section{Hutan Agroforestri}

Hutan agroforestri di LMDH Paniis RPH Rancakalong BKPH Manglayang Timur KPH Sumedang merupakan kawasan hutan produksi yang beralih fungsi menjadi hutan lindung.

Jenis-jenis pohon yang berada di hutan agroforestri di petak $4 \mathrm{G}$ dapat dilihat pada Tabel 2.

Tabel 2. Jenis-Jenis Pohon di Hutan Agroforestri Petak 4 G.

\begin{tabular}{rll}
\hline & \multicolumn{2}{c}{ Nama Pohon } \\
\cline { 2 - 3 } No & \multicolumn{1}{c}{ Lokal } & \multicolumn{1}{c}{ Latin } \\
\hline 1 & Cengkeh & Syzygium aromaticum \\
2 & Kopi & Coffea arabica \\
3 & Mahoni Daun Lebar & Swietenia macrophylla \\
4 & Pinus & Pinus mercusii \\
\hline
\end{tabular}

Sumber : Data primer.

Tabel 2 menunjukkan bahwa komposisi tanaman pada hutan agroforestri terdiri dari 4 spesies pohon yaitu pohon pinus pohon cengkeh, tanaman kopi dan pohon mahoni daun lebar. Dari 4 spesies yang ada di hutan agroforestri, tanaman kopi merupakan tanaman yang paling banyak karena memiliki jarak tanam yang lebih rapat yaitu $2,5 \mathrm{~m} \mathrm{x} 2,5 \mathrm{~m}$.

\section{Hutan Alam Primer}

Hutan alam primer di desa Pangadegan memiliki vegetasi yang beragam dengan kerapatan yang tinggi sehingga cahaya matahari yang dapat menembus tajuk pohon sangat kurang, mengakibatkan tanaman perdu ataupun anakan pohon sangat sulit untuk tumbuh. Berdasarkan kondisi tersebut maka tumbuhan yang ada di kawasan hutan ini dikategorikan sebagai kelas pohon besar. Jenis-jenis pohon yang berada di hutan alam primer dapat dilihat pada Tabel 3. 
Tabel 3. Jenis-Jenis Pohon di Hutan Alam Primer

\begin{tabular}{cll}
\hline \multirow{2}{*}{ No } & \multicolumn{2}{c}{ Nama Pohon } \\
\cline { 2 - 3 } & \multicolumn{1}{c}{ Lokal } & \multicolumn{1}{c}{ Latin } \\
\hline 1 & Baros & Manglietia glauca \\
2 & Beunying & Ficus Fistulosa \\
3 & Huru & Litsea angulata Bl. \\
4 & Kareumbi & Homalanthus populneus \\
5 & Kihujan & Samanea saman \\
6 & Kihuut & Simplocus sp. \\
7 & Kinangsi & Villebrunea rubescens \\
8 & Puspa & Schima walichii \\
9 & Rasamala & Altingia excelsa \\
10 & Saninten & Castanopsis argentea \\
11 & Waru Lot & Thespesia populnes \\
\hline
\end{tabular}

Sumber : Data Primer.

Tabel 3 menunjukkan bahwa komposisi tanaman pada hutan alam primer terdiri 11 spesies pohon yaitu Baros, Beunying, Huru, Kareumbi, Kihujan, Kihuut, Kinangsi, Puspa, Rasamala, Saninten dan Waru lot.

\section{Hutan Alam Sekunder}

Hutan alam sekunder di desa Pangadegan ini berbatasan dengan hutan agroforestri, sehingga memiliki kerapatan vegetasi yang jarang dan berdiameter kecil akibat tingginya aktivitas manusia yang masuk kedalam hutan tersebut diantaranya kegiatan berburu sehingga terjadi kerusakan vegetasi disebabkan jejak pemburu yang sering keluar masuk hutan sehingga terbentuk jalan setapak yang akhirnya dijadikan sebagai akses masuk kawasan. Selain itu mereka juga sering mengambil kayu sembarangan untuk kebutuhan rumah tangga. Jenis-jenis pohon yang berada di hutan alam sekunder dapat dilihat pada Tabel 4
Tabel 4. Jenis-jenis Pohon di Hutan Alam Sekunder

\begin{tabular}{cll}
\hline \multirow{2}{*}{ No } & \multicolumn{2}{c}{ Nama Pohon } \\
\cline { 2 - 3 } & \multicolumn{1}{c}{ Lokal } & \multicolumn{1}{c}{ Latin } \\
\hline 1. & Hantap & Sterculia coccinea \\
2. & Kibanen & Criyteronia paniculata \\
3. & Kibawang & Dysoxylum alliaceum \\
4. & Kibesi & Lindera sp. \\
5. & Kihuut & Simplocus sp. \\
6. & Kinangsi & Villebrunea rubescens \\
7. & Kitamiang & Celtis timorensis Span. \\
8. & Jamuju & Dacrycarpus imbricatus \\
9. & Kisireum & Eugenia cymose \\
10. & Puspa & Schima walichii \\
11. & Rasamala & Altingia excelsa \\
12. & Saninten & Castanopsis argentea \\
\hline
\end{tabular}

Sumber : Data primer.

Tabel 4 menunjukkan bahwa komposisi tanaman pada hutan alam sekunder terdiri 12 spesies pohon yaitu Hantap, Kibanten, Kibawang, Kibesi, Kihuut, Kinangsi, Kitamiang, Jamuju, Kisireum, Puspa, Rasamala dan Saninten.

\section{Pengukuran Cadangan Karbon}

1. Kerapatan Jenis

Berdasarkan hasil penelitian di lapangan, terdapat 4 spesies pohon di kawasan hutan agroforestri, sedangkan di hutan alam primer dan sekunder terdapat 18 spesies pohon. Dari jumlah total 22 spesies tersebut, baik dari hutan alam maupun hutan agroforestri diperoleh kerapatan jenisnya sebagaimana yang disajikan pada Tabel 5 dan Tabel 6. Nilai kerapatan jenis tersebut diperoleh dari Wood Density ICRAF-Database untuk 21 jenis pohon. Sedangkan 1 jenis pohon lainnya diperoleh dari pengujian di laboratorium THH Fahutan UNWIM, yang disajikan pada Tabel 7.

Tabel 5. Daftar Kerapatan Jenis Kayu di Hutan Agroforestri

\begin{tabular}{clcc}
\hline \multirow{2}{*}{ No } & \multicolumn{2}{c}{ Nama Pohon } & \multirow{2}{*}{$\begin{array}{c}\text { Kerapatan Jenis } \\
\left(\text { WD. g/cm }{ }^{3}\right)\end{array}$} \\
\cline { 2 - 3 } & Lokal & Lyatin & 0,70 \\
2 & Kopi & Coffea arabica & 0,62 \\
3 & Mahoni DL & Swietenia macrophylla & 0,50 \\
4 & Pinus & Pinus mercusii & 0,70 \\
\hline
\end{tabular}

Sumber : Data sekunder.

Keterangan: WD $\left(\mathrm{g} / \mathrm{cm}^{3}\right)=$ Wood Density ICRAF-Database. 
Tabel 6. Daftar Kerapatan Jenis Kayu di Hutan Alam Primer dan Sekunder

\begin{tabular}{|c|c|c|c|}
\hline \multirow{2}{*}{ No } & \multicolumn{2}{|c|}{ Nama Pohon } & \multirow{2}{*}{$\begin{array}{l}\text { Kerapatan Jenis } \\
\left(\mathrm{WD} \mathrm{g} / \mathrm{cm}^{3}\right)\end{array}$} \\
\hline & Lokal & Latin & \\
\hline 1. & Baros & Manglietia glauca & 0,41 \\
\hline 2. & Beunying & Ficus Fistulosa & 0,59 \\
\hline 3. & Hantap & Sterculia coccinea & 0,23 \\
\hline 4. & Huru & Litsea angulata Bl. & 0,45 \\
\hline 5. & Kareumbi & Homalanthus populneus & 0,36 \\
\hline 6. & Kibanen & Criyteronia paniculate & - \\
\hline 7. & Kibawang & Dysoxylum alliaceum & 0,65 \\
\hline 8. & Kibesi & Lindera sp. & 0,65 \\
\hline 9. & Kihujan & Samanea saman & 0,61 \\
\hline 10. & Kihuut & Simplocus sp. & 0,57 \\
\hline 11. & Kinangsi & Villebrunea rubescens & 0,62 \\
\hline 12. & Kitamiang & Celtis timorensis Sp.. & 0,72 \\
\hline 13. & Jamuju & Dacrycarpus imbricatus & 0,42 \\
\hline 14. & Kisireum & Eugenia cymose & 0,72 \\
\hline 15. & Puspa & Schima walichii & 0,75 \\
\hline 16. & Rasamala & Altingia excelsa & 0,81 \\
\hline 17. & Saninten & Castanopsis argentea & 0,73 \\
\hline 18. & Waru Lot & Thespesia populnea & 0,58 \\
\hline
\end{tabular}

Sumber : Data sekunder. WD g/ $\mathrm{cm}^{3}$

Keterangan: WD $\left(\mathrm{g} / \mathrm{cm}^{3}\right)=$ Wood Density ICRAF-Database .

Tabel 7. Hasil Penghitungan Kerapatan Jenis di Laboratorium THH Fahutan UNWIM

\begin{tabular}{|c|c|c|c|c|c|c|c|c|}
\hline \multirow{2}{*}{ No } & \multicolumn{2}{|c|}{ Nama Pohon } & \multicolumn{2}{|c|}{ Sub-contoh } & \multirow{2}{*}{$\begin{array}{c}\mathrm{K} \\
(\mathrm{cm})\end{array}$} & \multirow{2}{*}{$\begin{array}{c}\mathrm{T} \\
(\mathrm{cm})\end{array}$} & \multirow{2}{*}{$\mathrm{V}\left(\mathrm{cm}^{3}\right)$} & \multirow{2}{*}{$\mathrm{KJ}\left(\mathrm{g} / \mathrm{cm}^{3}\right)$} \\
\hline & Lokal & Latin & BB & BK & & & & \\
\hline 1. & anen & Criyteronia paniculata & 50,06 & 24,72 & 10 & 7 & 47,77 & 0,52 \\
\hline
\end{tabular}

Sumber : Data primer (diolah).

Keterangan :

$\mathrm{BB}=$ Berat basah $(\mathrm{g}), \mathrm{BK}=$ Berat kering $(\mathrm{g}), \mathrm{K}=$ Keliling $(\mathrm{cm}), \mathrm{T}=$ Tinggi $(\mathrm{cm}), \mathrm{V}=$ Volume $\left(\mathrm{cm}^{3}\right), \mathrm{KJ}=$ Kerapatan jenis $\left(\mathrm{g} / \mathrm{cm}^{3}\right)$ 
Tabel 7 menunjukkan bahwa kerapatan jenis yang dihitung di laboratorium yaitu Kibanen memiliki berat basah 50,06 g dan berat kering 24,72 $\mathrm{g}$ dengan kerapatan jenis sebesar $0.53 \mathrm{~g} / \mathrm{cm}^{3}$.

\section{Jumlah Cadangan Karbon}

a. Hutan Agroforestri

Hutan agroforestri di desa Pangadegan memiliki luas 17,14 ha terdiri dari pohon Pinus Mahoni daun lebar, Cengkeh dan Kopi. Hasil perhitungan cadangan karbon di hutan agroforestri dapat dilihat pada Tabel 8 berikut.

Tabel 8. Hasil Perhitungan Cadangan Karbon di Kawasan Hutan Agroforestri.

\begin{tabular}{ccr}
\hline Ukuran Plot & \multicolumn{2}{c}{$\sum$ Cadangan Karbon $(\mathrm{Kg})$} \\
\cline { 2 - 3 }$(\mathrm{m})$ & $\mathrm{Ha}$ & \multicolumn{1}{c}{ Kawasan } \\
\hline $40 \times 5$ & 197,15 & $3.379,20$ \\
$100 \times 20$ & $1.672,58$ & $28.668,00$ \\
\hline Jumlah & $1.869,73$ & $32.047,20$ \\
\hline
\end{tabular}

Sumber : Data primer (diolah).

Tabel 8 di atas menunjukkan bahwa cadangan karbon tersimpan pada kawasan hutan agroforestri seluas 17,14 hektar adalah sebanyak $32.047,20 \mathrm{~kg}$ atau $1.869,73 \mathrm{~kg}$ per hektar.

\section{b. Hutan Alam Primer}

Hutan alam primer di desa Pangadegan memiliki luas 17,12 ha terdiri dari pohon Baros, Kihuut, Kihujan, Puspa, Rasamala, Saninten, Beunying, Huru, Kareumbi, Kinangsi, Puspa dan Waru lot. Hasil perhitungan cadangan karbon di hutan alam primer dapat dilihat pada Tabel 9 berikut.

Tabel 9. Hasil Perhitungan Cadangan Karbon di Kawasan Hutan Alam Primer

\begin{tabular}{crr}
\hline Ukuran Plot & \multicolumn{2}{c}{$\sum$ Cadangan Karbon $(\mathrm{Kg})$} \\
\cline { 2 - 3 }$(\mathrm{m})$ & \multicolumn{1}{c}{ Ha } & \multicolumn{1}{c}{ Kawasan } \\
\hline $40 \times 5$ & 92,01 & $1.575,20$ \\
$100 \times 20$ & $2.526,31$ & $43.250,20$ \\
\hline Jumlah & $2.618,32$ & $44.825,60$ \\
\hline
\end{tabular}

Sumber : Data primer (diolah).
Tabel 9 di atas menunjukkan bahwa cadangan karbon tersimpan pada kawasan hutan alam primer seluas 17,12 hektar adalah sebanyak $44.825,60 \mathrm{~kg}$ atau $2.618,32 \mathrm{~kg}$ per hektar.

\section{c. Hutan Alam Sekunder}

Hutan alam primer di desa Pangadegan memiliki luas 132,85 hektar terdiri dari pohon Kibanen, Kibawang, Kibesi, Kihuut, Kinangsi, Kitamiang, Puspa, Rasamala, Hantap, Kisireum, Jamuju dan Saninten. Hasil perhitungan cadangan karbon di hutan alam sekunder dapat dilihat pada Tabel 10 berikut.

Tabel 10. Hasil Perhitungan Cadangan Karbon di Kawasan Hutan Alam Sekunder

\begin{tabular}{ccr}
\hline Ukuran Plot & \multicolumn{2}{c}{$\sum$ Cadangan Karbon $(\mathrm{Kg})$} \\
\cline { 2 - 3 }$(\mathrm{m})$ & $\mathrm{Ha}$ & \multicolumn{1}{c}{ Kawasan } \\
\hline $40 \times 5$ & 359,86 & $47.808,00$ \\
$100 \times 20$ & $1.101,05$ & $146.274,80$ \\
\hline Jumlah & $1.460,91$ & $194.082,80$ \\
\hline
\end{tabular}

Sumber : Data primer (diolah).

Tabel 10 di atas menunjukkan bahwa cadangan karbon tersimpan pada kawasan hutan alam sekunder seluas 132,85 hektar adalah sebanyak $194.082,80 \mathrm{~kg}$ atau $1.460,91$ $\mathrm{kg}$ per hektar.

Berdasarkan informasi yang disajikan pada Tabel 8, Tabel 9 dan Tabel 10 dapat dilihat bahwa hutan alam sekunder memiliki cadangan karbon lebih rendah dibandingkan dengan hutan agroforestri dan hutan alam primer. Hal tersebut disebabkan karena hutan alam sekunder memiliki kerapatan vegetasi yang jarang dan berdiameter kecil dibandingkan dengan hutan alam primer dan hutan agroforestri, meskipun hutan agroforestri memiliki variasi tanaman lebih sedikit. Kondisi tersebut selaras dengan pernyataan Hairiah et all (2011) bahwa jumlah cadangan karbon antar lahan berbedabeda, tergantung pada keanekaragaman dan kerapatan tumbuhan yang ada, jenis tanah serta cara pengolahannya. Demikian juga disampaikan oleh Kusmana (1993) bahwa faktor iklim seperti suhu dan curah hujan merupakan faktor yang mempengaruhi laju peningkatan karbon biomassa pohon. 


\section{KESIMPULAN}

Komposisi hutan agroferestri di LMDH Paniis RPH Rancakalong BKPH Manglayang Timur KPH Sumedang dengan luasan 17,14 ha terdiri dari pohon pinus (Pinus mercusii), mahoni daun lebar (Swietenia macrophylla), cengkeh (Syzygium aromaticum) dan kopi (Coffea arabica). Hutan agroforestri memiliki cadangan karbon $1.869,73 \mathrm{Kg} / \mathrm{ha}$, hutan alam primer memiliki cadangan karbon 2.618,32 $\mathrm{Kg} / \mathrm{ha}$ dan hutan alam sekunder memiliki cadangan karbon 1.460,91 Kg/ha. Sehingga hutan agroforestri memiliki cadangan karbon lebih tinggi di bandingkan dengan hutan alam sekunder namun lebih rendah dibandingkan hutan alam primer. Hal ini disebabkan karena hutan alam sekunder memiliki kerapatan vegetasi yang jarang dan pohon-pohonnya berdiameter kecil dibandingkan dengan hutan alam primer dan hutan agroforestri.

Perlu dilakukan penelitian lebih lanjut mengenai cadangan karbon pada sistem agroforestri dengan komposisi tanaman yang berbeda untuk mengetahui cadangan karbon yang tersimpan.

\section{UCAPAN TERIMA KASIH}

Kami menghaturkan terima kasih kepada Lembaga Penelitian dan Pengabdian kepada Masyarakat Universitas Winaya Mukti dan Fakultas Kehutanan Universitas Winaya Mukti atas dukungan dan fasilitas yang diberikan dalam penelitian ini. Juga kepada LMDH Paniis, pemerintah Desa Pangadegan dan Perum Perhutani atas izin dan dukungan mereka pada kami dalam melakukan penelitian ini.

\section{DAFTAR PUSTAKA}

Hairiah, K., A. Ekadinata, R.R. Sari, and S. Rahayu. 2011. Pengukuran Cadangan Karbon: Dari Tingkat Lahan ke Bentang Lahan. Petunjuk praktis. 2nd ed. World Agroforestry Center, ICRAF SEA Regional office, University of Brawijaya. (UB), Malang, Indonesia., Bogor.

Hairiah, K., and S. Subekti. 2007. Pengukuran 'Karbon Tersimpan' di Berbagai Macam Penggunaan Lahan. World Agroforestry Centre, ICRAF Southeast Asia, Bogor. Kauppi, P.E. 2003. New, Low Estimate for Carbon Stock in Global Forest Vegetation Based on Inventory Data.
Silva Fenn. 37(4): 451-457.

Kusmana, C. 1993. A Study of mangrove forest management base and ecological data in East Sumatera, Indonesia.

Utami, S.R., Bruno, V. Noordwijk, K.H.M. V Mustofa, and A. S. 2003. Bahan Ajaran Agroforestri 9: Prospek Penelitian dan Pengembangan Agroforestri di Indonesia. World Agroforestry Centre (ICRAF), Bogor.

Widianto, K. H., D. S., and M.A. S. 2003. Fungsi dan Peran Agroforestri. World Agroforestry Centre (ICRAF), Bogor. 